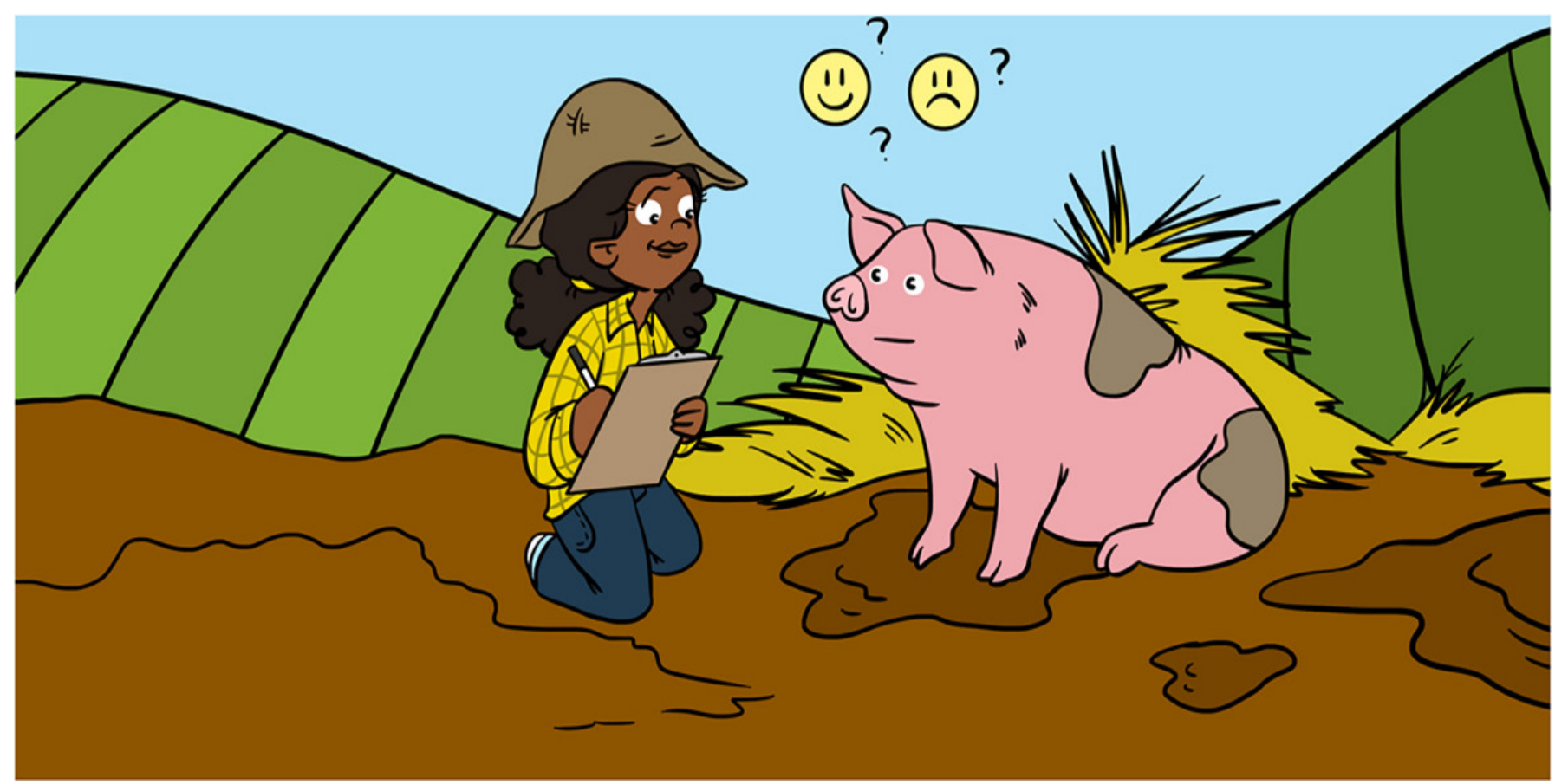

\title{
ANIMAL EMOTIONS-DO ANIMALS FEEL AS WE DO?
}

\section{Annika Krause ${ }^{* t}$ and Christian Nawroth ${ }^{*}$}

Institute of Behavioural Physiology, Research Institute for Farm Animal Biology (FBN), Dummerstorf, Germany

YOUNG REVIEWERS:

CLUB

DIVULGACIE-

NCIA

AGES: $12-13$
Emotions are an essential part of how we experience our world. Humans can express emotions by telling others how we feel-but what about animals? How can we tell whether they experience emotions and, if they do, which ones? When we think about the animals under human care, it is not only scientifically interesting but also ethically important to understand how these animals experience their worlds. Over the last 20 years, researchers have made considerable progress by identifying ways to assess emotions in animals. For example, researchers can look at the facial expressions of animals, record their vocalisations, or measure body processes such as changes in the heartbeat or hormone concentrations in the blood. This information can tell us more about how animals feel, why and how emotions have evolved, and what we, as humans, share with animals in our emotional experience of the world around us.

\section{WHAT ARE EMOTIONS AND WHY DO WE EXPERIENCE THEM?}

Emotions play a central role in our lives. But if we are asked, we might find it hard to describe what an emotion actually is! It is difficult to 


\section{PHYSIOLOGY}

Summary of all organic processes and phenomena of an organism. know how many different emotions there are, or whether everyone experiences certain emotions in the same way. What we know for sure is that emotions arise from the activity of nerve cells in several parts of the brain. Emotions can be described as pleasant (positive) or unpleasant (negative) and more arousing or less arousing, which refers to the intensity of the emotion [1]. When we experience emotions, they are often linked to changes in our behaviour and our physiology, which means the functions of our bodies, such as changes in posture, blood pressure, sweating, or heartbeat. For example, imagine you see a bear approaching you in the forest. What would you feel? Probably fear! The emotion of fear would probably be accompanied by a fearful facial expression and a rising heart rate, and would probably result in you running away.

But why do we experience emotions at all? While emotions are intangible and hard to describe-even for scientists-they serve important purposes. Emotions help us learn, initiate actions, and survive by adapting to new and sudden changes in the environment. Emotions change how we think, to prepare us to quickly select an appropriate response, such as running away when you see a bear approaching. Our behaviour can help us to avoid situations that evoke negative emotions (harm or punishment), or to seek out situations that generate positive emotions, such as joy. From an evolutionary perspective, experiencing emotions increases our ability to survive and reproduce.

\section{DO ANIMALS EXPERIENCE EMOTIONS?}

Since animals cannot tell us how they feel, how can we know whether they experience emotions? Because animal emotions are difficult to see, the question of whether animals experience emotions has historically been a philosophical one. Researchers have only started to investigate the emotional lives of animals in the past few decades. But when we think about farm animals, or any other animal under human care, it is not only scientifically interesting but also ethically important to try to understand how these animals emotionally experience their worlds. Farm animals are often kept in very large numbers in rather barren environments. This might lead to sickness, stress, and decreased well-being. If we could tell how animals emotionally experience their situations, this could help us to improve animal welfare. As we have already seen, emotional processes are complex and include feelings, behaviours, and physiological changes. Feelings are especially hard to assess in animals because they cannot tell us how they feel. However, when emotional things happen (such as when you see a bear approaching you), they cause changes in several biological processes. Based on these changes, researchers developed a wide set of methods to monitor emotions in animals, by measuring changes on the behavioural or physical levels, often at the same time (Figure 1) [2]. 
Figure 1

There are a variety of behavioural and physiological parameters that scientists can use to assess emotions in animals.

\section{GRIMACE SCALE}

A methods of pain assessment for non-human animals that is based on changes in a number of "facial action units" in the animal, such as narrowing of the eyes.

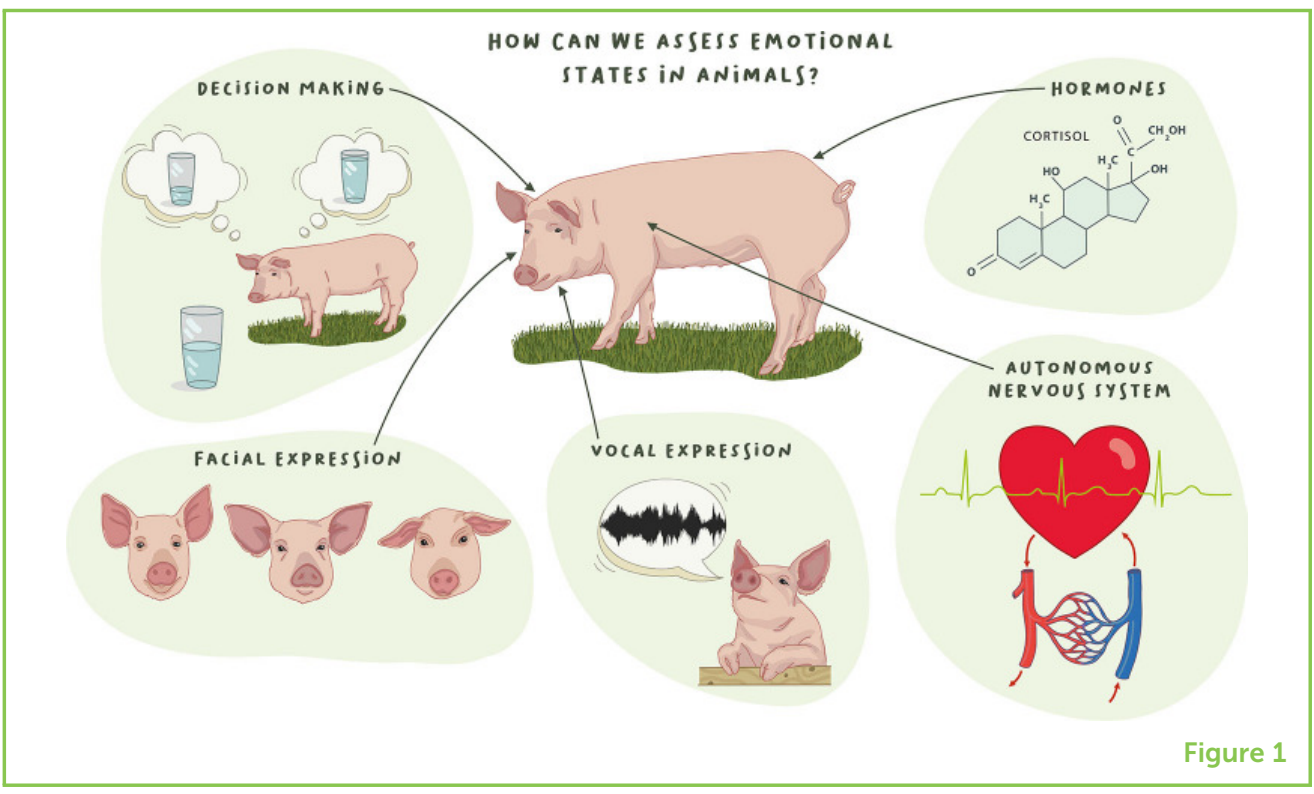

\section{MEASURING THE BEHAVIOURAL COMPONENT OF ANIMAL EMOTIONS}

The most easily detectable reaction of an animal to an event is how it changes its behaviour. Humans often change facial expressions and gestures depending on whether we experience an event as pleasant or not. If you look at your friends' faces, you can often very quickly assess if they are happy, fearful, angry, or disgusted. Animals show these characteristic facial expressions as well! So called grimace scales for horses, pigs, sheep, rats, mice, and cats have already been developed. For example, changes in ear position, the amount of visible eye white, and tension in the chewing muscles can indicate different levels of pain or fear in animals (Figure 1). It is important to remember that the facial expressions of animals usually look different than those of humans-joy might not be indicated by a smile (showing your teeth is often a signal of stress in other primates), while sadness is not accompanied by tears (pigs do not cry). In addition, prey animals (including all farm animals) tend not to show emotions that indicate pain or distress, as this might make them more vulnerable to predators.

Another example of animal behaviour that is linked to emotions involves vocalisations, such as grunts, bleats, and moos, which can indicate stress in many species. We know this is true for humans, too: imagine you are singing a song in front of many people; your voice might get shaky if you are nervous or experiencing stage fright. Researchers have found that the vocalisations of pigs, goats, and cows also change and get less harmonious when these animals are under stress, for example when they are isolated from the group, indicating negative emotions [3]. 
AUTONOMIC

NERVOUS SYSTEM

(ANS)

Part of the nervous system that acts largely unconsciously and regulates bodily functions including heart rate, blood pressure, respiration, and digestion.

SYMPATHETIC NERVOUS SYSTEM

Part of the ANS that is responsible for preparing the body for action, particularly in situations threatening survival. It increases heart rate, constricts blood vessels, and raises blood pressure.

PARASYMPATHETIC NERVOUS SYSTEM

Part of the ANS that is responsible for stimulation of activities that occur when the body is at rest, especially after eating. It decreases heart rate, and increases intestinal and gland activity.

HEART RATE

The number of heart beats per minute.

HEART RATE

VARIABILITY

It is a measure of the variance in time between the beats of the heart and can be affected by the emotions and the stress that we currently experience.

\section{HORMONES}

Chemical messengers that carry information throughout the body. They are produced by glands and travel in the bloodstream to tissues and organs.
Our decision-making is also influenced by the emotions we experience. For example, we know that humans who are in a bad mood tend to judge situations more negatively compared to humans who are in a positive mood. We all know the saying about the glass being either half full or half empty, depending on how you look at it. Interestingly, this also appears to be the case for animals (Figure 1). Farm animals, such as pigs and horses, make more cautious and pessimistic decisions after a negative event and more optimistic decisions after a positive event [4], and sheep pay closer attention to negative events when they are in a bad mood. However, we must always keep in mind that behaviour in animal species can differ depending on the situation, and we need to be cautious when we interpret animal behaviour to assess emotions.

\section{MEASURING THE PHYSIOLOGICAL COMPONENT OF ANIMAL EMOTIONS}

Physiological changes are central to emotions, as they play an important role in preparing animals for potentially dangerous situations. These changes include the activity of the nervous system and the levels of certain hormones.

The autonomic nervous system regulates bodily functions including heart rate, blood pressure, respiration, and digestion. Changes in autonomic nervous system activity can be used to study emotions in animal species. This is so because the two major subsystems of the autonomic nervous system-the sympathetic (activating) and parasympathetic (deactivating) systems-are directly connected to the heart. Based on emotions and stress, the complex interaction of these two subsystems causes variations in both heart rate and the time between heartbeats, which is called heart rate variability [5]. But what exactly can these changes in heart rate and heart rate variability tell us about emotions? Parasympathetic activity tells us whether an animal experiences a situation as positive or negative, whereas sympathetic activity tells us whether an animal experiences low or high arousal, which means the level of attention and alertness toward the environment. In our bear example, your experience of the emotion of fear will be accompanied by an increased heartbeat (high sympathetic activity) and less variability in your heart beats (low parasympathetic activity). Researchers have found that animal and human nervous systems react in similar ways in fearful situations. This indicates that many emotions in animals physiologically mirror those in humans.

Another physiological reaction to emotions in both humans and animals involves changes in hormone concentrations. In stressful situations, an increase in a hormone called adrenaline immediately reduces the blood supply to all organs that are not absolutely needed in an emergency. At the same time, the blood flow to important 
organs such as the brain, heart, and lungs is increased. The hormone noradrenaline provides increased alertness, and cortisol provides the energy to deal with stressful situations. Other hormones, such as dopamine, serotonin, and oxytocin, play important roles in joy, enthusiasm, and social bonding.

\section{WHY SHOULD WE CARE IF ANIMALS EXPERIENCE EMOTIONS?}

From all this research, it seems that the similarities between human and animal emotions might be closer than we would have expected a few decades ago. Animals react to their environments much as humans do. They respond emotionally to others and they evaluate situations in a similar way, becoming stressed and anxious in times of danger. While we may never know exactly how animals feel, studies have found that there are definite behavioural and physiological similarities in emotional expressions between humans and animals. We can thus infer, with quite some confidence, that animals can feel emotions. The more we discover about the behavioural and physiological components of emotions in animals, the more we understand about emotions, including our own ones, and how they affect the way we behave in our world.

The evidence of emotions in animals might also encourage us to re-think the environments in which we keep the animals that are under our care-on farms, in zoos, or in our houses. If we can better understand how animals interact and react to their environments, we can ultimately improve these environments, and thus improve human-animal relationships. It must be our ethical goal to decrease the negative emotions these animals experience, as well as to increase their experience of positive emotions.

\section{REFERENCES}

1. Mendl, M., Burman, O. H. P., and Paul, E. S. 2010. An integrative and functional framework for the study of animal emotion and mood. Proc $R$ Soc $B$. 277:2895-904. doi: 10.1098/Rspb.2010.0303

2. Paul, E. S., Harding, E. J., and Mendl, M. 2005. Measuring emotional processes in animals: the utility of a cognitive approach. Neurosci Biobehav Rev. 29:469-91. doi: 10.1016/j.Neubiorev.2005.01.002

3. Briefer, E. F. 2012. Vocal expression of emotions in mammals: mechanisms of production and evidence. J Zool. 288:1-20. doi: 10.1111/J.1469-7998.2012. 00920.X

4. Roelofs, S., Boleij, H., Nordquist, R. E., and van der Staay, F. J. 2016. Making decisions under ambiguity: judgment bias tasks for assessing emotional state in animals. Front Behav Neurosci. 10:119. doi: 10.3389/Fnbeh.2016.00119

5. von Borell, E., Langbein, J., Després, G., Hansen, S., Leterrier, C., Marchant-Forde, J., et al. 2007. Heart rate variability as a measure of autonomic regulation of 
cardiac activity for assessing stress and welfare in farm animals-a review. Physiol Behav. 92:293-316. doi: 10.1016/j.physbeh.2007.01.007

SUBMITTED: 29 October 2020; ACCEPTED: 18 October 2021; PUBLISHED ONLINE: 17 November 2021.

EDITED BY: Stuart Semple, University of Roehampton London, United Kingdom

CITATION: Krause A and Nawroth C (2021) Animal Emotions-Do Animals Feel as We Do? Front. Young Minds 9:622811. doi: 10.3389/frym.2021.622811

CONFLICT OF INTEREST: The authors declare that the research was conducted in the absence of any commercial or financial relationships that could be construed as a potential conflict of interest.

COPYRIGHT @ 2021 Krause and Nawroth. This is an open-access article distributed under the terms of the Creative Commons Attribution License (CC BY). The use, distribution or reproduction in other forums is permitted, provided the original author(s) and the copyright owner(s) are credited and that the original publication in this journal is cited, in accordance with accepted academic practice. No use, distribution or reproduction is permitted which does not comply with these terms.

\section{YOUNG REVIEWERS}

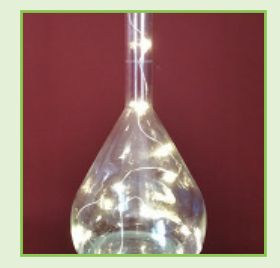

\section{CLUB DIVULGACIENCIA, AGES: 12-13}

Members of Divulgaciencia are students from secondary school highly motivated in science and technology. This working team focus on communication and scientific dissemination. We enjoy looking for scientific channels, videos, publications, and conferences for general public to increase our knowledge and learn about communication skills. In this review students from IES Santa Eugenia (Madrid) and IES Profesor Domínguez Ortiz (Azuqueca de Henares) have been involved.
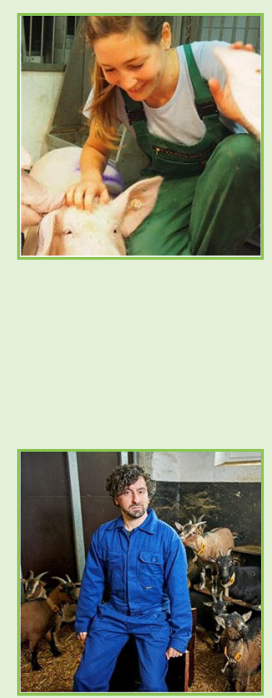

\section{AUTHORS}

\section{ANNIKA KRAUSE}

Annika is a behavioural biologist at the Leibniz-Institute for Farm Animal Biology, and she investigates emotions in farm animals, especially pigs. With her studies, she tries to understand how emotions are mediated by physiological and behavioural processes and how personality may shape emotional experiences in animals. Her research aims at a better understanding of the complexity of emotional states in animals, which plays a significant role in improving farm animal conditions and welfare. *krause@afbn-dummerstorf.de

\section{CHRISTIAN NAWROTH}

Christian is a trained biologist and a researcher at the Leibniz-Institute for Farm Animal Biology, where he is currently working on a project that asks how domestication and the selection for high milk yield has changed behaviour 
and problem-solving abilities in goats. He is interested in how animals interact with their physical and social environments, and his research focuses on the mental capacities of farm (goats, horses, pigs, sheep) and zoo (great apes, penguins) animals and how this knowledge can be used to improve the animals' conditions and human-animal interactions. *nawroth.christianagmail.com; orcid.org/0000-0003-4582-4057

${ }^{\dagger}$ These authors have contributed equally to this work 